\title{
Neural connectivity in youth at-risk for bipolar disorder: a review of functional magnetic resonance imaging studies
}

Article $\cdot$ November 2017

DOI: $10.21035 /$ ijcnmh.2017.4(Suppl.3).S02

CITATIONS

0

5 authors, including:

Vítor Santos

Hospitais da Universidade de Coimbra

34 PUBLICATIONS 46 CITATIONS

SEE PROFILE

\section{Miguel Bajouco}

Hospitais da Universidade de Coimbra

30 PUBLICATIONS 77 CITATIONS

SEE PROFILE
READS

73

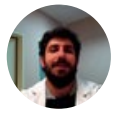

Manuel Coroa

Hospitais da Universidade de Coimbra

5 PUBLICATIONS 0 CITATIONS

SEE PROFILE

\section{Nuno Madeira}

Hospitais da Universidade de Coimbra

128 PUBLICATIONS 90 CITATIONS

SEE PROFILE

Some of the authors of this publication are also working on these related projects: 


\title{
Neural connectivity in youth at-risk for bipolar disorder: a review of functional magnetic resonance imaging studies
}

\author{
Vítor Santos ${ }^{1,2}$, Manuel Coroa ${ }^{1,2}$, Salomé Caldeira ${ }^{2}$, Miguel Bajouco, ${ }^{1,2}$, and Nuno Madeira ${ }^{1,2}$
}

Special Issue on the Neurobiology of Mental IIIness

\begin{abstract}
Background: Delayed diagnosis of bipolar disorder (BD) is common in adolescents and young adults and the search for biomarkers to help in early diagnosis in $\mathrm{BD}$ at-risk populations is an important goal of neuroimaging research. Functional connectivity studies in BD patients suggests that anomalous connectivity between prefrontal and limbic regions could be risk biomarkers for BD. The aim of this review is to provide an overview of the neuroimaging literature that employed functional connectivity techniques in adolescents and young adults at-risk for BD.
\end{abstract}

Methods: A literature search was conducted using PubMed and EMBASE databases, to identify fMRI studies that employed a measure of functional or effective connectivity or network based statistics and included individuals at-risk for BD who were in the age range of early-mid adolescence (13-18 years old) and/or young adulthood (19-25 years old).

Results: Ten studies focusing on 4 functional imaging domains were identified, namely emotion processing, affective cognition, reward processing and resting-state. Altered functional connectivity between amygdala and ventrolateral prefrontal cortex (PFC); amygdala and anterior cingulate cortex and between anterior cingulate cortex, ventrolateral PFC and dorsolateral PFC emerged as putative risk biomarkers. Heterogeneity in BD at-risk samples, tasks and connectivity analysis methods has been identified.

Conclusions: Youth at-risk for BD have altered functional connectivity in prefrontal-limbic networks supporting emotion regulation that might underlie emotion lability and mood dysregulation predisposing to BD. Future longitudinal studies in adolescents and young adults with Bipolar At-Risk criteria are important to establish functional connectivity measures as risk biomarkers.

Keywords: Bipolar Disorder, At-Risk, Functional Connectivity, fMRI.

'Department of Psychological Medicine, Faculty of Medicine of the University of Coimbra, University of Coimbra, Portugal

2Department of Psychiatry, Coimbra University Hospital Centre, Portugal
Citation: Santos et al. Neural connectivity in youth at-risk for bipolar disorder: a review of functional magnetic resonance imaging studies. International Journal of Clinical Neurosciences and Mental Health 2017; 4(Suppl. 3):S02 DOI: https://doi.org/10.21035/ijcnmh.2017.4(Suppl.3).S02 


\section{Introduction}

Bipolar disorder (BD) is a lifelong illness, characterized by recurrent episodes of depressed, elevated and mixed mood states interpolated by euthymic periods [1]. It is a disabling illness due to its early onset, severity and chronicity [2], with around $75 \%$ patients having a first mood episode in adolescence or early adulthood [3]. This early onset and the associated level of disability places $\mathrm{BD}$ as the 4th leading cause of global disease burden in adolescents and young adults [4].

Efficacious psychopharmacological and psychosocial treatments are available [5], but delayed diagnosis is common [6]. Mental health services are increasingly adopting a strategy to diagnose and treat $\mathrm{BD}$ as early as possible $[7,8]$, in order to prevent poor outcomes such as social and occupational disability and premature mortality from suicide and medical comorbidities [9-11]. However, the current approach to identify individuals at risk for BD, with an emphasis on clinical features, temperamental traits and family history, has insufficient predictive validity, with only a minority of 'at risk' individuals making the transition to $\mathrm{BD}$ $[8,12,13]$. The identification of biomarkers, a key goal of $\mathrm{BD}$ neuroimaging research, could increase the confidence of early diagnosis in adolescents and young adults [14].

Technical advances in neuroimaging methods have led to the conceptualization of the brain as a network of functionally connected and constantly interacting regions, requiring a focus on understanding patterns of connectivity as well as localized activation [15]. Task based connectivity analysis aims to assess changes in the strength of correlated activity among brain regions of interest when comparing different task conditions. In these analyses, it is important to distinguish undirected associations between brain regions (functional connectivity) from directed and causal relationships (effective connectivity) [16]. Resting-state functional connectivity studies are based on the collection of blood oxygenation level-dependent (BOLD) signal time-series in the absence of any task demands. The analysis of these data can take several forms, but all exploit the fact that brain regions with strong anatomical connections typically show organized spontaneous correlations in their functional activity over time [17]. A powerful tool for the study of functional brain networks is graph theory. Graph theory model the brain as a network comprised of nodes (voxels or brain regions) and edges (connections between nodes). This enables the analysis of functional interactions between every possible brain region, known as the functional connectome. Graph-theory metrics can be used to study the topological properties of such network. Network based statistics such as clustering-coefficient, characteristic path length, centrality, efficiency, modularity, among others, provide insights about functional integration, segregation, resilience or organization of the network as a whole or of its individual nodes $[18,19]$.
Findings indicate a variety of different patterns of abnormal functional connectivity in individuals with $\mathrm{BD}$, suggesting corticolimbic dysconnectivity as a possible biomarker [20]. Functional connectivity studies have focused predominantly on the amygdala and striatal-prefrontal cortical networks during emotional processing, emotional regulation, reward-processing and cognitive control tasks [21]. Several of these studies have shown, in individuals with BD, both abnormally increased positive functional connectivity between the amygdala and ventrolateral prefrontal cortex (PFC) or abnormally decreased inverse functional connectivity between these regions. Similar findings of enhanced connectivity have been observed using resting-state fMRI. Connectivity between the amygdala and medial prefrontal regions and between medial and lateral regions within the PFC has also been implicated in BD, but the direction of findings is less consistent. Recent studies have also demonstrated altered connectivity in reward-related networks, particularly the ventral striatum (VS) and its interactions with medial PFC [21].

However, studies in patients with BD do not allow the distinction of alterations linked to disease vulnerability from those associated with the clinical course, treatment and psychiatric comorbidities. Thus, one of the steps that is needed to elucidate neural network functional connectivity abnormalities in $\mathrm{BD}$, include examination of the development of functional brain networks in youth at risk for $\mathrm{BD}$, before the emergence of full-blown disorder. To our knowledge only one review reported results of functional connectivity analysis in relatives of patients with BD [22]. In this systematic review of $29 \mathrm{fMRI}$ studies, the authors included $2 \mathrm{BD}$ offspring studies that employed connectivity analyses (Psychophysiological Interaction - PPI). The authors concluded that first-degree relatives of $\mathrm{BD}$ patients showed changes in the same brain regions implicated in the pathophysiology of the disease in studies with $\mathrm{BD}$ patients, such as the inferior frontal gyrus (IFG), the medial PFC, the insula, the amygdala and the parietal lobe. However, this review focused in fMRI activation data and the authors considered the great heterogeneity of age range of the samples as a limitation of their study To date, there are no systematic reviews focused in fMRI connectivity data in at-risk populations at the peak age of incidence of BD.

The aim of this review is to provide an overview of the literature regarding findings from neuroimaging studies that employed functional connectivity techniques in samples with adolescents and young adults at-risk for BD.

\section{Methods}

\section{Literature search}

A computerized advanced search using the databases PubMed and EMBASE for articles published until $31 \mathrm{Au}-$ gust 2017 was conducted using the following key search terms: "bipolar disorder" AND (at-risk OR high risk OR genetic risk OR offspring) AND "connectivity". The ref- 
erence lists of articles meeting the inclusion criteria were also searched manually for relevant articles.

\section{Study selection}

Studies were included if they: (i) used fMRI (task based and/or resting state); (ii) employed a measure of functional or effective connectivity or network based statistics; (iii) included individuals in the age range of early-mid adolescence (13-18 years old), and/or young adulthood (19-25 years old); (iv) included a group of individuals with genetic or clinical risk for $\mathrm{BD}$ (offspring of patients with $\mathrm{BD}$; youth with Bipolar at-risk criteria) and a comparison group; and (v) were published in English in a peer-review journal. We did not exclude studies where overlapping samples (i.e., the same cohort of patients) were used, although these will be identified as such when reviewed below.

\section{Results}

Figure 1 summarizes the review process. The search identified 127 studies. After removal of duplicates, screening and assessment for eligibility, 10 articles met the inclusion criteria and were selected for review. No additional article was found in the manual search. Most of the studies were conducted in adolescents [23-30] with only two studies conducted in young adults $[31,32]$. The samples of subjects at-risk for BD were comprised of healthy offspring of bipolar patients $[25,28,29]$, healthy and symptomatic offspring of bipolar patients $[24,26,27,30]$, symptomatic offspring of bipolar patients [23] and healthy and symptomatic offspring or siblings of bipolar patients $[31,32]$. Some studies were conducted by the same research groups, with partially overlapping samples $[23,26,27,30][25,28,29][31,32]$.

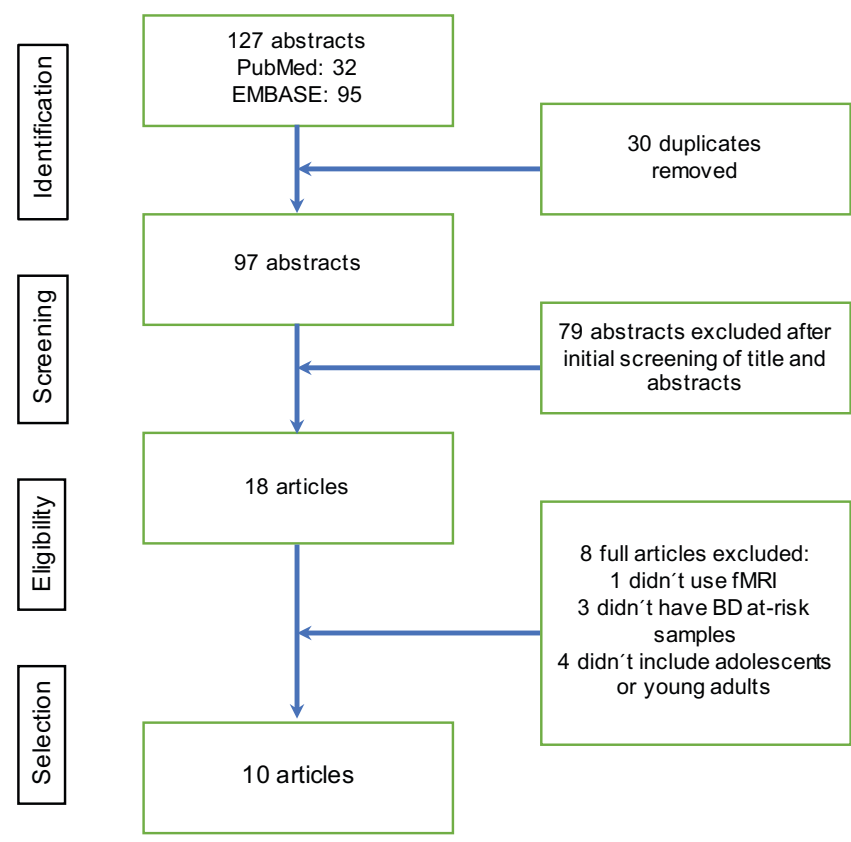

Figure 1. Flowchart of review process and study selection.
The studies focused in 4 functional imaging domains: 2 studies employed an emotion processing task [23,26]; 2 studies employed a cognitive-affective task [25,31]; 3 studies employed a reward processing task $[27,28,30]$ and 3 were resting state fMRI studies [24,29,32]. Table 1 resume the main methodological characteristics and results of the selected studies.

\section{Emotion processing}

Manelis and colleagues [26] performed a fMRI study with an implicit facial emotion processing paradigm, 'the dynamic faces task' [33]. The authors compared the functional connectivity between offspring of parents with BD, offspring of non-bipolar parents and controls, employing psychophysiological interaction (PPI) analysis. The seed region was the right amygdala and target regions comprise the anterior cingulate cortex, orbitofrontal cortex and ventrolateral PFC. They found that the offspring of parents with BD showed significantly more negative right amygdala-anterior cingulate cortex functional connectivity to emotional faces versus shapes, but significantly more positive right amygdala-left ventrolateral PFC functional connectivity to happy faces than the offspring of non-bipolar parents and controls.

In a recent study, Chang and colleagues [23] compared functional connectivity between symptomatic offspring of parents with BD and controls, using an explicit facial emotion processing task. Using psychophysiological interaction (PPI) analysis with the amygdala as the seed region and the rest of the brain as target regions, the authors found that the offspring of parents with $\mathrm{BD}$, compared to the control group, had significantly greater connectivity between the amygdala and visual cortex and between the amygdala and right ventrolateral PFC.

\section{Affective cognition}

Ladoucer and colleagues [25] also employed psychophysiological interaction (PPI) analysis to measure functional connectivity in healthy offspring of parents with BD and controls, using ventrolateral PFC as seed region and the amygdala and dorsolateral PFC as target regions. An fMRI with an emotional working memory paradigm, 'the emotional face N-Back task' [34], was performed in both groups. With fearful face distracters, offspring of parents with $\mathrm{BD}$, compared to the control group, had significantly reduced ventrolateral PFC modulation of the right amygdala. With happy face distracters, offspring of parents with $\mathrm{BD}$ had significantly reduced ventrolateral PFC modulation of the left amygdala and less functional connectivity between right ventrolateral PFC and left dorsolateral PFC.

Breakspear and colleagues [31] used a different method of connectivity analysis, dynamic causal modelling, to infer patterns of effective connectivity underlying the interaction of motor inhibition and fear perception. Using an emotional face go-no go task, the authors compared 
Table 1. Main methods and results of functional connectivity studies in individuals at-Risk for BD.

\begin{tabular}{|c|c|c|c|c|}
\hline First Author, Year & $\begin{array}{l}\text { Participants } \\
\text { (number, mean age) }\end{array}$ & Paradigm & $\begin{array}{l}\text { Connectivity } \\
\text { Analysis }\end{array}$ & Results in At-Risk BD \\
\hline $\begin{array}{l}\text { Breakspear, } 2015 \\
{[31]}\end{array}$ & $\begin{array}{l}41 \text { At-Risk BD }(24,4) \\
55 \mathrm{BD}(25,0) \\
45 \mathrm{HC}(23,3)\end{array}$ & $\begin{array}{l}\text { Emotional face Go/ } \\
\text { No-Go task }\end{array}$ & $\begin{array}{l}\text { Dynamic causal } \\
\text { modeling }\end{array}$ & $\begin{array}{l}\text { Marked difference in the hierarchical influ- } \\
\text { ence of the ACC from the DLPFC to the IFG }\end{array}$ \\
\hline Chang, 2017 [23] & $\begin{array}{l}50 \text { At-Risk BD }(13,5) \\
29 \mathrm{HC}(13,6)\end{array}$ & $\begin{array}{l}\text { Explicit facial emo- } \\
\text { tion processing task }\end{array}$ & $\begin{array}{l}\text { Psychophysiologi- } \\
\text { cal interaction }\end{array}$ & $\begin{array}{l}\text { Greater connectivity between the amygdala } \\
\text { and 1) visual cortex and 2) right VLPFC }\end{array}$ \\
\hline Collin, 2017 [24] & $\begin{array}{l}60 \text { At-Risk BD }(14,2) \\
28 \text { At-Risk SZ }(13,1) \\
23 \mathrm{HC}(12,7)\end{array}$ & Resting state & $\begin{array}{l}\text { Graph theory } \\
\text { analysis }\end{array}$ & $\begin{array}{l}\text { No connectivity deficits of the brain's central } \\
\text { rich club system. Increased coupling between } \\
\text { structural and functional connectivity (SC-FC } \\
\text { coupling) of long-distance connections }\end{array}$ \\
\hline Ladoucer, 2013 [25] & $\begin{array}{l}16 \text { At-Risk BD }(14,2) \\
15 \mathrm{HC}(13,8)\end{array}$ & $\begin{array}{l}\text { Emotional working } \\
\text { memory task }\end{array}$ & $\begin{array}{l}\text { Psychophysiologi- } \\
\text { cal interaction }\end{array}$ & $\begin{array}{l}\text { Reduced connectivity between VLPFC and the } \\
\text { right amygdala with fearful face distracters } \\
\text { and reduced connectivity between 1) VLPFC } \\
\text { and the left amygdala and } 2 \text { ) right VLPFC and } \\
\text { left DLPFC with happy face distracters }\end{array}$ \\
\hline Manelis, 2015 [26] & $\begin{array}{l}29 \text { At-Risk BD }(13,8) \\
29 \text { NBO }(13,8) \\
23 \mathrm{HC}(13,7)\end{array}$ & $\begin{array}{l}\text { Implicit facial emo- } \\
\text { tion processing task }\end{array}$ & $\begin{array}{l}\text { Psychophysiologi- } \\
\text { cal interaction }\end{array}$ & $\begin{array}{l}\text { More negative right amygdala-ACC functional } \\
\text { connectivity to emotional faces versus shapes, } \\
\text { but more positive right amygdala-left VLPFC } \\
\text { functional connectivity to happy faces }\end{array}$ \\
\hline Manelis, 2016 [27] & $\begin{array}{l}29 \text { At-Risk BD }(13,8) \\
29 \mathrm{NBO}(13,8) \\
23 \mathrm{HC}(13,7)\end{array}$ & $\begin{array}{l}\text { Card number guess- } \\
\text { ing game }\end{array}$ & $\begin{array}{l}\text { Psychophysiologi- } \\
\text { cal interaction }\end{array}$ & $\begin{array}{l}\text { Greater negative functional connectivity be- } \\
\text { tween the bilateral VS and the right VLPFC }\end{array}$ \\
\hline Roberts, 2017 [32] & $\begin{array}{l}71 \text { At-Risk BD }(24,4) \\
49 \mathrm{BD}(25,0) \\
80 \mathrm{HC}(23,3)\end{array}$ & Resting state & $\begin{array}{l}\text { Graph theory } \\
\text { analysis }\end{array}$ & $\begin{array}{l}\text { Weaker functional connectivity between IFG } \\
\text { and insular regions and the ACC }\end{array}$ \\
\hline Singh, 2014 [28] & $\begin{array}{l}20 \text { At-Risk BD }(12,7) \\
29 \mathrm{HC}(11,8)\end{array}$ & $\begin{array}{l}\text { Monetary incentive } \\
\text { delay task }\end{array}$ & $\begin{array}{l}\text { Psychophysiologi- } \\
\text { cal interaction }\end{array}$ & $\begin{array}{l}\text { Weaker functional connectivity between the } \\
\text { pregenual ACC and the right VLPFC while } \\
\text { anticipating rewards but stronger connectiv- } \\
\text { ity between these regions while anticipating } \\
\text { losses }\end{array}$ \\
\hline Singh, 2014 [29] & $\begin{array}{l}24 \text { At-Risk BD }(12,2) \\
23 \mathrm{HC}(13,7)\end{array}$ & Resting state & $\begin{array}{l}\text { Independent com- } \\
\text { ponent analysis } \\
\text { (ICA) and region } \\
\text { of interest (ROI) } \\
\text { based intrinsic } \\
\text { connectivity }\end{array}$ & $\begin{array}{l}\text { ICA: increased connectivity in the VLPFC sub- } \\
\text { region of the left ECN. ROI-based analyses: } \\
\text { decreased connectivity between 1) the left } \\
\text { amygdala and pregenual ACC, 2) the subgen- } \\
\text { ual ACC and supplementary motor cortex, and } \\
\text { 3) the left VLPFC and left caudate. }\end{array}$ \\
\hline Sohener, 2016 [30] & $\begin{array}{l}25 \text { At-Risk BD }(13,8) \\
21 \text { NBO }(13,8)\end{array}$ & $\begin{array}{l}\text { Card number guess- } \\
\text { ing game }\end{array}$ & $\begin{array}{l}\text { Psychophysiologi- } \\
\text { cal interaction }\end{array}$ & $\begin{array}{l}\text { More VS-left posterior insula connectivity. In- } \\
\text { creased VS-left posterior insula connectivity } \\
\text { and VS-left anterior insula/VLPFC connectivity } \\
\text { were associated with greater mood dysregula- } \\
\text { tion }\end{array}$ \\
\hline
\end{tabular}

ACC: Anterior Cingulate Cortex; BD: Bipolar Disorder; DLPFC: Dorsolateral Prefrontal Cortex; ECN: Executive Control Network; HC: Healthy Controls; ICA: Independent Component Analysis; IFG: Inferior Frontal Gyrus; NBO: Non-Bipolar Offspring; ROI: Region of Interest; SZ: Schizophrenia; VLPFC: Ventrolateral Prefrontal Cortex; VS: Ventral Striatum

four bilinear and four non-linear models of the effective connectivity between the nodes specified by the model: left fusiform gyrus and primary visual cortex for stimulus input, left anterior cingulate cortex for the effect of fear, left dorsolateral PFC for the effect of motor inhibition and left inferior frontal gyrus (IFG) for the interaction of fear and inhibition. The authors reported a marked difference in the hierarchical influence of the anterior cingulate on the effective connectivity from the dorsolateral PFC to the inferior frontal gyrus that is unique to the at-risk cohort, suggesting distinct brain network mechanisms for the integration of cognitive control and emotion perception in these clinical population.

The first study [28] that compared functional connectivity data between healthy offspring of parents with BD and controls using a reward processing task ('the monetary incentive delay task') employed psychophysiological interaction (PPI) analysis. The seed region was the pregenual cingulate and the target regions the bilateral amygdalae, insula, nucleus accumbens and ventrolateral PFC. Offspring of parents with BP had weaker functional connectivity between the pregenual cingulate and the right ventrolateral PFC while anticipating rewards than did controls but had a stronger connectivity between these regions while anticipating losses.

Manelis and colleagues [27] compared the functional connectivity between offspring of parents with $\mathrm{BD}$, offspring of non-bipolar parents and controls, employing psychophysiological interaction (PPI) analysis to data of an fMRI study with a reward processing paradigm, 'the card number-guessing game' [35]. The seed region was bilateral ventral striatum and the target regions comprised bilateral 
anterior cingulate cortex, medial PFC, orbitofrontal cortex, ventrolateral PFC and insula. There was a significant main effect of group on functional connectivity between the bilateral ventral striatum and the right ventrolateral prefrontal cortex, with the offspring of parents with BD showing significantly greater negative functional connectivity than other participants.

Using the same reward processing paradigm and the same method of functional connectivity analysis, Soehner and colleagues [30] compared the offspring of parents with $\mathrm{BD}$ with the offspring of non-bipolar parents and correlated the functional connectivity results with sleeping and mood dysregulation data obtained from psychometric instruments. The authors found that the offspring of parents with BD showed significantly more ventral striatum-left posterior insula connectivity than offspring of non-bipolar parents. Sleep duration and ventral striatum-left anterior insula/ventrolateral PFC connectivity were negatively related in the offspring of parents with $\mathrm{BD}$, but positively related in the offspring of non-bipolar parents. Additionally, increased ventral striatum-left posterior insula connectivity and ventral striatum-left anterior insula/ventrolateral PFC connectivity were associated with greater mood dysregulation only in the offspring of parents with BD.

\section{Resting state fMRI}

Singh and colleagues [29] compared resting state fMRI data between the offspring of parents with $\mathrm{BD}$, offspring of non-bipolar parents and controls, using two connectivity analysis methods: data-driven independent component analysis (ICA) and hypothesis-driven region-of-interest (ROI) based intrinsic connectivity. In the ROI analysis, the authors have selected neural circuits that underlie emotional and inhibitory control: the left and right amygdala, the left and right ventrolateral PFC, and the subgenual anterior cingulate. Four out of the 25 group functional networks, including the dorsal and ventral default mode (DMN) and the executive control (ECN) networks, were selected a priori. ICA revealed that, relative to low-risk youth, high-risk youth showed increased connectivity in the ventrolateral PFC subregion of the left executive control network (ECN), which includes frontoparietal regions important for emotion regulation. ROI-based analyses revealed that high-risk versus low-risk youth had decreased connectivity between the left amygdala and pregenual cingulate, the subgenual cingulate and supplementary motor cortex, and between the left ventrolateral PFC and left caudate.

Roberts and colleagues [32] performed between-group analyses of the left IFG functional connectivity and used graph theory to study its local functional network topology. Machine learning was used to study classification based solely upon the functional connectivity of the IFG. In BD patients, the left IFG was functionally disconnected from a network of regions including bilateral insula, ventrolateral prefrontal gyri, superior temporal gyri and the putamen. A small network incorporating neighboring insular regions and the anterior cingulate cortex showed weaker functional connectivity in at-risk for BD subjects when compared to controls. These regions overlapped with frontolimbic regions which a machine learning classifier selected as predicting group membership with an accuracy significantly greater than chance.

In a recent multimodal imaging study, Collin and colleagues [32] performed resting state fMRI and diffusion-weighted MRI scans to compare the structural and functional connectome in offspring of bipolar patients, offspring of schizophrenia (SZ) patients and controls. Anatomical and functional brain networks were reconstructed and examined using graph theoretical analysis to study anatomical connectome topology, rich club organization and functional communities. The authors also analyzed structural-functional coupling between at-risk groups and controls. The SZ offspring were found to show connectivity deficits of the brain's central rich club system relative to both controls and the BD offspring. The disruption in anatomical rich club connectivity in SZ offspring was associated with increased modularity of the functional connectome. In addition, increased coupling between structural and functional connectivity (SC-FC coupling) of long-distance connections was observed in both SZ and BD offspring. The finding of no rich club deficits in the offspring of $\mathrm{BD}$ patients suggest a differential effect of genetic predisposition for schizophrenia versus bipolar disorder on the developmental formation of the connectome.

\section{Discussion}

In this article, we have systematically reviewed the available fMRI functional and effective connectivity studies in adolescents and young adults at-risk for $\mathrm{BD}$, to provide a comprehensive account of the literature to date. Collectively, the literature provides evidence for a role of frontolimbic network anomalous connection patterns in the development of BD. The findings are consistent with reviews of functional connectivity neuroimaging research in patients with $\mathrm{BD}[20,21]$ which suggests that alterations of functional connectivity are putative risk biomarkers for the disorder.

Altered functional connectivity between prefrontal regions, including the ventrolateral PFC, dorsolateral PFC and anterior cingulate cortex (ACC), as well as closely related subcortical areas including the amygdala, ventral striatum and insula, were present during tasks of emotional processing, affective cognition, reward-based decision-making and resting-state conditions in samples with healthy and symptomatic offspring of parents with $\mathrm{BD}$. These results are compatible with the consensus model of the functional neuroanatomy of BD [36] which hypothesized that the disease arises from dysfunction of brain networks that modulate emotional behavior. In this model, two ventral prefrontal networks are similarly organized to form iterative feedback loops that process information and modulate the amygdala 
and other limbic brain areas. One network originates in the ventrolateral PFC and modulate emotion states generated by external emotional cues, such as with affective face tasks. The other network originates in the ventromedial PFC (orbitofrontal cortex) and modulate emotional states generated by stimuli that arise from internal feeling states, such as paradigms that involve inducing an emotional response to personalized events. Additionally, different voluntary and automatic emotion regulation subprocesses have been identified, centered on the ventrolateral and ventromedial prefrontal cortices, respectively.

Despite the variability of results related to heterogeneity of the samples, connectivity analysis techniques and tasks, three frontolimbic dysconnectivity patterns emerged: altered connectivity between the ventrolateral PFC and the amygdala, altered connectivity between the ACC and the amygdala and altered connectivity between the ventrolateral PFC, dorsolateral PFC and ACC. Altered connectivity between the ventrolateral PFC and the amygdala, with individuals atrisk for $\mathrm{BD}$ showing more functional connectivity between these regions during emotion processing tasks $[23,26]$ and less functional connectivity during affective cognitive tasks [25], partially overlaps with findings of abnormally heightened functional connectivity between the amygdala and ventrolateral PFC during rest or emotional processing in BD patients [21]. Abnormally high connectivity between the amygdala and ventrolateral PFC may represent a lack of flexibility to incorporate feedback from other neocortical areas, such as the dorsolateral PFC and ACC, that may predispose youths to the development of mood dysregulation and eventually $\mathrm{BD}$ [37]. This is also compatible with findings in $\mathrm{BD}$ at-risk subjects of more negative right amygdala -ACC functional connectivity during emotional processing tasks [26], decreased connectivity between the left amygdala and pregenual cingulate [29] in resting state and prefrontal dysconnectivity patterns during emotional cognition tasks $[25,31]$ and resting state $[29,32]$.

Ventrolateral PFC (and the partial overlapping region of Inferior Frontal Gyrus) emerged as an important node of the frontolimbic networks showing functional connectivity alterations in adolescents and young adults at-risk for BD, with reports of altered functional connectivity in studies of all functional domains (emotional processing, affective cognition, reward processing and resting state studies). The ventrolateral PFC is implicated in psychological processes of emotion self-regulation [38] and social regulation of emotion [39]. Emotion regulation can be conceptualized in terms of multiple valuation mechanisms and is initiated by a second-order valuation system that assigns value to the emotional feelings that were generated by a first-order valuation system [38]. In this model, emotion generation results from an initial perception-valuation-action (PVA) cycle, and emotion regulation results from a second PVA cycle that takes the initial emotion as the target of perception that is itself evaluated. When there is a discrepancy between desired and actual emotions, specific emotion regulation strategies (situation selection or modification; attentional deployment; reappraisal; response modulation) are then evaluated to determine which to implement. Ventrolateral PFC may contribute to these high-level appraisal mechanisms that assign value to ongoing emotional states and to emotion regulatory strategies [40] and anomalous patterns of functional connectivity with other cortical and subcortical brain regions could be a neural substrate of emotional lability and mood dysregulation in BD at-risk individuals.

One important limitation of the studies included in this review is that some subcortical and prefrontal regions were analyzed as a single brain region, despite important subdivisions with different functions and connectivity profiles. The amygdala has distinct subregions with structurally and functionally distinct nuclei. The primary nuclei complexes- basolateral (BL) and centromedial (CM)have been found to have different patterns of connectivity with prefrontal and subcortical networks during the processing of emotional material, with the CM complex typically connecting with sensory and autonomic areas and the BL complex connecting with motor and prefrontal areas [41]. Similarly, the ACC has important subdivisions, with different profiles of functional connectivity and functional specialization [40]. Subgenular ACC is important for the appraisal of viscero-motor signals based on anticipated interaction with the environment and drives changes in physiological arousal while the pregenular ACC is relatively specialized in the appraisal of viscero-sensory signals based on conceptual meaning and implications for self, contributing to subjective feelings of pleasure and displeasure. The dorsal ACC appears to be preferentially in appraisal of actions based on expected outcomes, motor costs, task context and social goals [40]. Future functional neuroimaging connectivity studies in BD at-risk populations should take into account these different subdivisions in order to provide a more detailed understanding of the developmental trajectory of functional connectivity anomalies predisposing to $\mathrm{BD}$.

Another limitation found in this review is the absence of studies in high-risk clinical populations without family history of BD. Although BD has a high heritability $[42,43]$, the presence of a positive family history does not have a good clinical utility for case finding in adolescents and young adults with a history of depressive episodes, due to their low prevalence in general psychiatric samples and because a significant proportion of the offspring of $\mathrm{BD}$ patients will continue to suffer from depressive disorder. Other temperamental characteristics, such as cyclothymia, have a better clinical utility for case finding in depressed youth at-risk of early transition for BD [13]. Neuroimaging studies in adolescents and young adults with a history of depressive episodes, assessed with dimensional measures of cyclothymia and categorical Depression Bipolar At-Risk (BAR-D) criteria, are an important future research avenue to find functional connectivity risk markers that predict future conversion to BD. 
There is also a clear need for longitudinal studies, with cohorts of adolescents and young adults with BAR-D criteria, integrating functional connectivity data from neuroimaging studies with clinical information and data from peripheral blood-based and smartphone-based electronic biomarkers [44]. Machine learning techniques may also be used to assess individuals at risk for $\mathrm{BD}$, transforming data into applicable information about the individual risk for conversion to $\mathrm{BD}$. In this sense, machine learning may allow to develop personalized interventions to prevent the transition from at-risk states to full-blown illness [45].

\section{Conclusion}

In summary, the findings of this qualitative systematic review in youth at-risk for $\mathrm{BD}$ are compatible with the consensus model of the functional neuroanatomy of BD [36] and are also consistent with reviews of functional connectivity neuroimaging research in patients with $\mathrm{BD}[20,21]$ which suggests that alterations of functional connectivity are putative risk biomarkers for the disorder. Ventrolateral PFC emerged as an important node of the frontolimbic networks showing functional connectivity alterations in adolescents and young adults at-risk for $\mathrm{BD}$. The ventrolateral PFC role in high-level appraisal mechanisms that assign value to ongoing emotional states and to emotion regulatory strategies could be impaired due to anomalous patterns of functional connectivity with other cortical and subcortical brain regions, underlying the emotional lability and mood dysregulation predisposing to $\mathrm{BD}$ in at-risk adolescents and young adults.

\section{Abbreviations}

ACC: Anterior Cingulate Cortex; BAR-D Bipolar At-Risk Depression; BD: Bipolar Disorder; BL: Basolateral; BOLD: Blood Oxigenation Level Dependent; CM: Centromedial; DMN: Default Mode Network; ECN: Executive Control Network; fMRI: Functional Magnetic Resonance Imaging; ICA: Independent Component Analysis; IFG: Inferior Frontal Gyrus; MRI: Magnetic Resonance Imaging; PFC: Prefrontal Cortex; PPI: Psychophysiological Interaction; PVA: Perception-Valuation-Action; ROI: Region-of-Interest; SC-FC: Structural-Functional; SZ: Schizophrenia; VS: Ventral Striatum

\section{Acknowledgments}

Work supported by the Faculty of Medicine of the University of Coimbra and Santander Totta Bank, grant reference FMUC-BST-2016-174.

\section{Competing interests}

The authors declare no conflict of interest.

\section{References}

1. Grande I, Berk M, Birmaher B, Vieta E. Bipolar disorder. The Lancet $2016 ; 387(10027): 1561-72$. https://doi.org/10.1016/S0140-6736(15)00241-X

2. Ferrari AJ, Stockings E, Khoo JP, Erskine HE, Degenhardt L, Vos T, Whiteford HA. The prevalence and burden of bipolar disorder: findings from the Global Burden of Disease Study 2013. Bipolar disorders 2016; 18(5):440-50. https://doi.org/10.1111/bdi.12423
3. Geoffroy PA, Leboyer M, Scott J. Prédire le trouble bipolaire: que pouvons-nous apprendre des études prospectives de cohortes? L'Encéphale 2015; 41(1):10-6.

https://doi.org/10.1016/j.encep.2013.05.004

4. Gore FM, Bloem PJ, Patton GC, Ferguson J, Joseph V, Coffey C, Sawyer SM, Mathers CD. Global burden of disease in young people aged 10-24 years: a systematic analysis. The Lancet 2011; 377(9783):2093-102. https://doi.org/10.1016/S0140-6736(11)60512-6

5. Carvalho AF, Vieta E, editors. The Treatment of Bipolar Disorder: Integrative Clinical Strategies and Future Directions. Oxford University Press; 2017. https://doi.org/10.1093/med/9780198748625.001.0001

6. Dagani J, Signorini G, Nielssen O, Bani M, Pastore A, Girolamo GD, Large M. Meta-analysis of the interval between the onset and management of bipolar disorder. The Canadian Journal of Psychiatry 2017; 62(4):247-58. https://doi.org/10.1177/0706743716656607

7. Rios AC, Noto MN, Rizzo LB, Mansur R, Martins Jr FE, Grassi-Oliveira R, Correll CU, Brietzke E. Early stages of bipolar disorder: characterization and strategies for early intervention. Revista Brasileira de Psiquiatria 2015; 37(4):343-9. https://doi.org/10.1590/1516-4446-2014-1620

8. Geoffroy PA, Scott J. Prodrome or risk syndrome: what's in a name?. International journal of bipolar disorders 2017;5(1):7. https://doi.org/10.1186/s40345-017-0077-5

9. Forte A, Baldessarini RJ, Tondo L, Vázquez GH, Pompili M, Girardi P. Long-term morbidity in bipolar-I, bipolar-II, and unipolar major depressive disorders. Journal of affective disorders 2015;178:71-8. https://doi.org/10.1016/j.jad.2015.02.011

10. Hayes JF, Miles J, Walters K, King M, Osborn DP. A systematic review and meta-analysis of premature mortality in bipolar affective disorder. Acta Psychiatrica Scandinavica 2015; 131(6):417-25. https://doi.org/10.1111/acps.12408

11. Schaffer A, Isometsä ET, Tondo L, H Moreno D, Turecki G, Reis C, Cassidy F, Sinyor M, Azorin JM, Kessing LV, Ha K. International Society for Bipolar Disorders Task Force on Suicide: meta-analyses and meta-regression of correlates of suicide attempts and suicide deaths in bipolar disorder. Bipolar disorders 2015; 17(1):1-6. https://doi.org/10.1111/bdi.12271

12. Bechdolf A, Ratheesh A, Cotton SM, Nelson B, Chanen AM, Betts J, Bingmann T, Yung AR, Berk M, McGorry PD. The predictive validity of bipolar at-risk (prodromal) criteria in help-seeking adolescents and young adults: a prospective study. Bipolar disorders 2014; 16(5):493-504. https://doi.org/10.1111/bdi.12205

13. Scott J, Marwaha S, Ratheesh A, Macmillan I, Yung AR, Morriss R, Hickie IB, Bechdolf A. Bipolar at-risk criteria: an examination of which clinical features have optimal utility for identifying youth at risk of early transition from depression to bipolar disorders. Schizophrenia bulletin 2016; sbw154.

14. Phillips ML, Swartz HA. A critical appraisal of neuroimaging studies of bipolar disorder: toward a new conceptualization of underlying neural circuitry and a road map for future research. American Journal of Psychiatry 2014; 171(8):829-43. https://doi.org/10.1176/appi.ajp.2014.13081008

15. Soares JM, Magalhães R, Moreira PS, Sousa A, Ganz E, Sampaio A, Alves V, Marques P, Sousa N. A hitchhiker's guide to functional magnetic resonance imaging. Frontiers in neuroscience 2016; 10. https://doi.org/10.3389/fnins.2016.00515

16. Friston KJ. Functional and effective connectivity: a review. Brain connectivity $2011 ; 1(1): 13-36$. https://doi.org/10.1089/brain.2011.0008

17. Smitha KA, Akhil Raja K, Arun KM, Rajesh PG, Thomas B, Kapilamoorthy TR, Kesavadas C. Resting state fMRI: A review on meth- 
ods in resting state connectivity analysis and resting state networks. The Neuroradiology Journal 2017; 1971400917697342. https://doi.org/10.1177/1971400917697342

18. Bullmore ET, Bassett DS. Brain graphs: graphical models of the human brain connectome. Annual review of clinical psychology 2011; 7:113-40

https://doi.org/10.1146/annurev-clinpsy-040510-143934

19. Fornito A, Zalesky A, Bullmore E. Fundamentals of brain network analysis. Academic Press; 2016.

20. Vai B, Bollettini I, Benedetti F. Corticolimbic connectivity as a possible biomarker for bipolar disorder. Expert review of neurotherapeutics 2014; 14(6):631-50. https://doi.org/10.1586/14737175.2014.915744

21. Chase HW, Phillips ML. Elucidating neural network functional connectivity abnormalities in bipolar disorder: toward a harmonized methodological approach. Biological psychiatry: cognitive neuroscience and neuroimaging 2016; 1(3):288-98.

22. Piguet C, Fodoulian L, Aubry JM, Vuilleumier P, Houenou J. Bipolar disorder: functional neuroimaging markers in relatives. Neuroscience \& Biobehavioral Reviews 2015; 57:284-96. https://doi.org/10.1016/j.neubiorev.2015.08.015

23. Chang K, Garrett A, Kelley R, Howe M, Sanders EM, Acquaye T, Bararpour L, Li S, Singh M, Jo B, Hallmayer J. Anomalous prefrontal-limbic activation and connectivity in youth at high-risk for bipolar disorder. Journal of Affective Disorders 2017; 222:7-13. https://doi.org/10.1016/j.jad.2017.05.051

24. Collin G, Scholtens LH, Kahn RS, Hillegers MH, van den Heuvel MP. Affected Anatomical Rich Club and Structural-Functional Coupling in Young Offspring of Schizophrenia and Bipolar Disorder Patients. Biological Psychiatry 2017. https://doi.org/10.1016/j.biopsych.2017.06.013

25. Ladouceur CD, Diwadkar VA, White R, Bass J, Birmaher B, Axelson DA, Phillips ML. Fronto-limbic function in unaffected offspring at familial risk for bipolar disorder during an emotional working memory paradigm. Developmental cognitive neuroscience 2013; 5:185-96. https://doi.org/10.1016/j.dcn.2013.03.004

26. Manelis A, Ladouceur CD, Graur S, Monk K, Bonar LK, Hickey MB, Dwojak AC, Axelson D, Goldstein BI, Goldstein TR, Bebko G. Altered amygdala-prefrontal response to facial emotion in offspring of parents with bipolar disorder. Brain 2015; 138(9):2777-90. https://doi.org/10.1093/brain/awv176

27. Manelis A, Ladouceur CD, Graur S, Monk K, Bonar LK, Hickey MB, Dwojak AC, Axelson D, Goldstein BI, Goldstein TR, Bebko G. Altered functioning of reward circuitry in youth offspring of parents with bipolar disorder. Psychological medicine 2016; 46(1):197-208. https://doi.org/10.1017/S003329171500166X

28. Singh MK, Kelley RG, Howe ME, Reiss AL, Gotlib IH, Chang KD. Reward processing in healthy offspring of parents with bipolar disorder. JAMA psychiatry 2014; 71(10):1148-56. https://doi.org/10.1001/jamapsychiatry.2014.1031

29. Singh MK, Chang KD, Kelley RG, Saggar M, Reiss AL, Gotlib IH. Early signs of anomalous neural functional connectivity in healthy offspring of parents with bipolar disorder. Bipolar disorders 2014; 16(7):678-89.

https://doi.org/10.1111/bdi.12221

30. Soehner AM, Bertocci MA, Manelis A, Bebko G, Ladouceur CD, Graur S, Monk K, Bonar LK, Hickey MB, Axelson D, Goldstein BI. Preliminary investigation of the relationships between sleep duration, reward circuitry function, and mood dysregulation in youth offspring of parents with bipolar disorder. Journal of affective disorders 2016; 205:144-53. https://doi.org/10.1016/j.jad.2016.03.074

31. Breakspear M, Roberts G, Green MJ, Nguyen VT, Frankland A, Levy F, Lenroot R, Mitchell PB. Network dysfunction of emotional and cognitive processes in those at genetic risk of bipolar disorder. Brain
$2015 ; 138(11): 3427-39$.

https://doi.org/10.1093/brain/awv261

32. Roberts G, Lord A, Frankland A, Wright A, Lau P, Levy F, Lenroot RK, Mitchell PB, Breakspear M. Functional dysconnection of the inferior frontal gyrus in young people with bipolar disorder or at genetic high risk. Biological psychiatry 2017; 81(8):718-27. https://doi.org/10.1016/j.biopsych.2016.08.018

33. Perlman SB, Fournier JC, Bebko G, Bertocci MA, Hinze AK, Bonar L, Almeida JR, Versace A, Schirda C, Travis M, Gill MK. Emotional face processing in pediatric bipolar disorder: evidence for functional impairments in the fusiform gyrus. Journal of the American Academy of Child \& Adolescent Psychiatry 2013; 52(12):1314-25. https://doi.org/10.1016/j.jaac.2013.09.004

34. Ladouceur CD, Silk JS, Dahl RE, Ostapenko L, Kronhaus DM, Phillips ML. Fearful faces influence attentional control processes in anxious youth and adults. Emotion 2009; 9(6):855. https://doi.org/10.1037/a0017747

35. Forbes EE, Brown SM, Kimak M, Ferrell RE, Manuck SB, Hariri AR. Genetic variation in components of dopamine neurotransmission impacts ventral striatal reactivity associated with impulsivity. Molecular psychiatry 2009; 14(1):60. https://doi.org/10.1038/sj.mp.4002086

36. Strakowski SM, Adler CM, Almeida J, Altshuler LL, Blumberg HP, Chang KD, DelBello MP, Frangou S, McIntosh A, Phillips ML, Sussman JE. The functional neuroanatomy of bipolar disorder: a consensus model. Bipolar disorders 2012; 14(4):313-25. https://doi.org/10.1111/j.1399-5618.2012.01022.x

37. Chang KD. Amygdalar-Prefrontal Connectivity Changes During Adolescence: Implications for Development of Mood Disorders. Biological Psychiatry 2017; 82(7):458-9. https://doi.org/10.1016/j.biopsych.2017.07.022

38. Gross JJ, editor. Handbook of emotion regulation. Guilford publications; 2013.

39. Reeck C, Ames DR, Ochsner KN. The social regulation of emotion: An integrative, cross-disciplinary model. Trends in cognitive sciences 2016; 20(1):47-63. https://doi.org/10.1016/j.tics.2015.09.003

40. Dixon ML, Thiruchselvam R, Todd R, Christoff K. Emotion and the prefrontal cortex: an integrative review. Psychol Bull 2017. https://doi.org/10.1037/bul0000096

41. Kerestes R, Chase HW, Phillips ML, Ladouceur CD, Eickhoff SB. Multimodal evaluation of the amygdala's functional connectivity. NeuroImage 2017; 148:219-29. https://doi.org/10.1016/j.neuroimage.2016.12.023

42. McGuffin P, Rijsdijk F, Andrew M, Sham P, Katz R, Cardno A. The heritability of bipolar affective disorder and the genetic relationship to unipolar depression. Archives of general psychiatry 2003; 60(5):497-502. https://doi.org/10.1001/archpsyc.60.5.497

43. Lichtenstein P, Yip BH, Björk C, Pawitan Y, Cannon TD, Sullivan PF, Hultman CM. Common genetic determinants of schizophrenia and bipolar disorder in Swedish families: a population-based study. The Lancet 2009; 373(9659):234-9. https://doi.org/10.1016/S0140-6736(09)60072-6

44. Kessing LV, Munkholm K, Faurholt-Jepsen M, Miskowiak KW, Nielsen LB, Frikke-Schmidt R, Ekstrøm C, Winther O, Pedersen BK, Poulsen HE, McIntyre RS. The Bipolar Illness Onset study: research protocol for the BIO cohort study. BMJ open 2017; 7(6):e015462. https://doi.org/10.1136/bmjopen-2016-015462

45. Librenza-Garcia D, Kotzian BJ, Yang J, Mwangi B, Cao B, Lima LN, Bermudez MB, Boeira MV, Kapczinski F, Passos IC. The impact of machine learning techniques in the study of bipolar disorder: A systematic review. Neuroscience \& Biobehavioral Reviews 2017; $80: 538-54$ https://doi.org/10.1016/j.neubiorev.2017.07.004 